\title{
Restraint-Stress-Induced Changes in Exploratory Behavior Appear to Be Mediated by Norepinephrine-Stimulated Release of CRF
}

\author{
Craig W. Berridge a and Adrian J. Dunn \\ Department of Neuroscience, University of Florida College of Medicine, Gainesville, Florida 32610
}

\begin{abstract}
Exploratory behavior, measured by the time an animal spends investigating objects in a novel environment, has been shown to be sensitive to prior exposure of the animal to stressors. Using this paradigm, it was demonstrated previously that both corticotropin-releasing factor (CRF) and the $\alpha_{2}$-adrenoreceptor antagonist, idazoxan, elicited stress-like decreases in exploratory behavior. Because an activation of cerebral noradrenergic systems is observed during stress, following intracerebroventricular (i.c.v.) administration of CRF, or following peripheral administration of idazoxan, the involvement of noradrenergic systems in the behavioral effect of restraint and CRF was examined.
\end{abstract}

Inhibition of norepinephrine (NE) release using the $\alpha_{2}$-agonist clonidine $(25 \mu \mathrm{g} / \mathbf{k g}$, i.p.) or the noradrenergicselective neurotoxin DSP-4 antagonized the restraint-induced decrease in exploratory behavior. The combination of these 2 treatments completely prevented this effect of restraint. The $\alpha_{1}$-receptor antagonist prazosin $(200 \mu \mathrm{g} / \mathrm{kg})$ also prevented the behavioral effect of restraint, whereas the $\alpha_{1}$-agonist phenylephrine (50 or $100 \mathrm{ng}$, i.c.v.) decreased exploratory behavior. None of these treatments consistently altered locomotor activity as measured by the number of entries into the different compartments or the number of rears. These results implicate noradrenergic systems in the stress-related changes in this behavior, consistent with our parallel measures of the production of NE catabolites. Thus, both CRF and noradrenergic systems appear to be involved in the effect of restraint on exploratory behavior in this task.

Neither DSP-4 nor prazosin had any effect on the CRF. induced decrease in exploratory behavior. However, the CRF antagonist $\alpha$-helical $\mathrm{CRF}_{9-41}(20 \mu$ g, i.c.v.) reversed the decrease in exploratory behavior induced by phenylephrine. The most likely explanation is that the 2 systems act in tandem such that noradrenergic systems regulate the release of brain CRF via an $\alpha_{1}$-adrenoreceptor. This arrangement parallels that involved in the release of hypothalamic CRF to activate the pituitary-adrenal axis. The implications of these results for research on stress-related behaviors and for the etiology of depression are discussed.

\footnotetext{
Received Oct. 31, 1988; revised Feb. 23, 1989; accepted Apr. 10, 1989.

We gratefully acknowledge the gift of CRF and ahCRF from Iean Rivier and of prazosin by Pfizer. This research was supported by the National Institute of Mental Health (MH25486) and a fellowship to C.W.B. (MH09680).

Correspondence should be addressed to Dr. Adrian J. Dunn, Department of Pharmacology and Therapeutics, Louisiana State University Medical Center, P.O. Box 33932, Shreveport, LA 71130-3932.

a Present address: Department of Psychiatry, University of California, San Diego, M-003, La Jolla, CA 92093.

Copyright (C) 1989 Society for Neuroscience $0270-6474 / 89 / 103513-09 \$ 02.00 / 0$
}

When released from the median eminence of the hypothalamus, corticotropin-releasing factor (CRF) is a critical regulator of the glucocorticoid response in stress. However, CRF (Swanson et al., 1983) and high-affinity binding sites for CRF have been identified in many areas of the brain (Wynn et al., 1984), and a $\mathrm{Ca}^{2+}$-dependent release of CRF was observed in many of these regions (Smith et al., 1986). When injected directly into the brain, CRF elicits a number of neurochemical, physiological, and behavioral responses that resemble those observed in stress (Brown et al., 1982; Morley and Levine, 1982; Sutton et al., 1982; Kalin et al., 1983; Berridge and Dunn, 1986; Dunn and Berridge, 1987). Results such as these prompted the hypothesis that CRF participates in coordinating a global, or whole-body, response in stress (Gold and Chrousos, 1985; Koob and Bloom, 1985). Supporting this hypothesis is the observation that a CRF antagonist, administered intracerebroventricularly (i.c.v.), reversed various stress-induced behavioral and physiological responses (Brown et al., 1986; Krahn et al., 1986; Rivier et al., 1986; Berridge and Dunn 1987a; Tazi et al., 1987).

Exploratory behavior, as measured by the mean time an animal spends investigating novel stimuli in a multicompartment chamber (MCC), is decreased following exposure to various stressors (Arnsten et al., 1985; Berridge and Dunn, 1986). In this paradigm, CRF injected i.c.v. in mice (Berridge and Dunn, 1986) and rats (C. W. Berridge, F. Spadaro, H. A. Baldwin, and A. J. Dunn, unpublished observations) elicited a stress-like decrease in exploratory behavior. A CRF antagonist, $\alpha$-helical $\mathrm{CRF}_{9-41}$ (ahCRF; Rivier et al., 1984), administered i.c.v. dose dependently reversed the behavioral effect of restraint stress in mice (Berridge and Dunn, 1987a). This result suggests that CRF acting within the brain participates in the restraint-induced change in exploratory behavior observed in the $\mathrm{MCC}$.

Central noradrenergic systems are also activated in stress (Stone, 1975; Dunn and Kramarcy, 1984). In an carlicr study, mice administered the $\alpha_{2}$-antagonist idazoxan at a dose $(1.0 \mathrm{mg}$ / $\mathrm{kg}$ ) that increases both norepinephrine (NE) release (Scheinin and Virtanen, 1986) and neuronal firing in the locus coeruleus (Goldstein et al., 1983) experienced a stress-like decrease in exploratory behavior when tested in the MCC (Berridge and Dunn, 1987b). In contrast, the $\alpha_{2}$-agonist clonidine $(25 \mu \mathrm{g} / \mathrm{kg}$ ), which inhibits NE release and locus coeruleus firing (Svensson et al., 1975; Warsh et al., 1981), increased exploratory behavior. These results suggested that noradrenergic systems regulate exploratory behavior in the MCC.

When injected i.c.v., CRF increased the basal firing rate of noradrenergic neurons in the locus coeruleus (Valentino et al., 1983) and increased the accumulation of the NE catabolite 3-methoxy,4-hydroxyphenylethyleneglycol (MHPG) in various brain regions (Dunn and Berridge, 1987). Therefore, it is pos- 
sible that CRF mediates stress-induced behavioral responding through an interaction with noradrenergic systems. However, NE has been demonstrated to stimulate CRF release from neurons of the hypothalamic paraventricular nucleus (PVN) (Plotsky, 1987; Szafarczyk et al., 1987). This site has also been implicated in regulating the behavioral effects of CRF (Krahn et al., 1988). Thus, during stress, noradrenergic neurons may regulate CRF release to alter behavioral responding. The sensitivity of exploratory behavior in the MCC to stress, CRF, and the modulation of NE release suggested that this paradigm might be useful for studying the involvement of NE in stress-induced behavioral responding and the potential interactions between CRF and NE in the brain.

\section{Materials and Methods}

Materials. Clonidine and phenylephrine were obtained from Sigma Chemical Co. (St. Louis, MO) and dissolved in normal saline $(0.17 \mathrm{M})$. Prazosin (a gift from Pfizer, Groton, CT) was dissolved in water at a concentration twice the desired concentration and diluted with an equal volume of 2-fold concentrated normal saline. DSP-4 (Astra) was dissolved in normal saline immediately before use. CRF and ahCRF were provided by Dr. Jean Rivier (Salk Institute). CRF was dissolved in normal saline and stored frozen. ahCRF was dissolved in water and brought to $50 \%$ normal saline concentration by the addition of the appropriate volume of 25 -fold concentrated normal saline.

Animals. Male CD-1 mice (25-35 gm) were obtained from Charles River (Wilmington, MA). They were group housed with free access to food and water for a minimum of 1 week before surgery and behavioral testing. All animals were maintained on a 12-12 hr light cycle (lights on 7 AM).

Surgery. In experiments requiring i.c.v. injections, polyethylene cannulae (Clay Adams PE-50 tubing) were implanted in the lateral cerebral ventricles 3-7 d before behavioral testing (Guild and Dunn, 1982). Surgery was performed under pentobarbital anesthesia. Cannula placement was verified by visual inspection following injection of dye through the cannulae.

Procedures. In experiments in which cannula implantation was not required, animals were group housed throughout the experiment. Cannulated animals were housed singly immediately following surgery. Behavioral testing was conducted between 0830 and 1600 .

Restrained animals were transferred to a room separate from both the colony and testing rooms and restrained for $40 \mathrm{~min}$ as previously described (Berridge and Dunn, 1986). Immediately following restraint, the animals were carried into the testing room and placed in the testing chamber. Unrestrained animals were transferred from the colony room to the testing room and immediately placed in the testing chamber.

All injections were administered in the colony room. In experiments involving administration of a drug to restrained animals, the injection was given $5 \mathrm{~min}$ before restraint. Unrestrained animals were injected and returned to their home cage where they remained until testing. All drugs were injected intraperitoneally (i.p.) except CRF, ahCRF, and phenylephrine, which were administered i.c.v. Unless otherwise stated, i.c.v. injections consisted of a total volume of $4 \mu$ l divided equally between the 2 cannulae and given over a $45 \mathrm{sec}$ period.

Behavioral testing. The experimental chamber used was based on that described by Arnsten et al. $(1981)$, scaled down $(38 \times 38 \times 23 \mathrm{~cm})$ for use with mice. This chamber consisted of 9 interconnecting compartments, within each of which a wire mesh stimulus $(3.0 \mathrm{~cm}$ sphere) was recessed in a $2.5 \mathrm{~cm}$ hole below the floor. Animals were placed in the chamber and observed for $25 \mathrm{~min}$, except for the experiment represented in Figure 5. During this observation period the duration and frequency of a number of behaviors were recorded by a trained observer unaware of experimental treatments. Each animal was observed separately. Behaviors were recorded as previously described (Berridge and Dunn, 1987a). The following behaviors were recorded: measures of contact with the stimuli-number of contacts, duration of contacts, mean time per contact (duration of contacts/number of contacts); measures of locomotor activity-compartment entries and rears, and time spent grooming.

$H P L C$ analysis of the biogenic amines and their catabolites. In certain experiments, each animal was removed from the observation room immediately following testing and transferred to the main laboratory, where it was decapitated. The brain was rapidly removed and dissected on ice into prefrontal medial cortex (PFM), nucleus accumbens (NAS), hypothalamus (HTH), hippocampus (HPC), and brain stem (BST), weighed, frozen on dry ice, and homogenized as previously described (Dunn et al., 1986). The supernatants were assayed for catecholamines, serotonin, and their metabolites by HPLC with electrochemical detection as previously described (Dunn et al., 1986; Dunn and Berridge, 1987). Experiments involving neurochemical analysis included a quietcontrol group that received no treatments before transport from the colony room and dissection of the brain.

Determination of plasma corticosterone concentrations. Plasma corticosterone was determined following extraction with methylene chloride by radioimmunoassay according to the procedure of GwosdowCohen et al. (1982) using the antibody of G. Niswender (Colorado State University). Cross-reactivity of the antibody with progesterone and cortisol was $<1 \%$, cortisone and testosterone was $<0.1 \%$, and estradiol and aldosterone was $<0.01 \%$. The sensitivity was $9 \mathrm{pg}$, and the coefficient of variation for the data presented was $8 \%$.

Statistical analysis. Statistical analysis was performed by ANOVA using an ANOVA statistical package (Human Systems Dynamics, Northridge, CA) on an Apple IIgs computer. When statistical significance was indicated by ANOVA (i.e., $p<0.05$ ), comparison of individual means was performed using Duncan's multiple-range test. For analysis of some neurochemical data involving the comparison of all experimental groups to one control group, Dunnett's $t$ test was used.

\section{Results}

Are noradrenergic systems involved in the restraintinduced decrease in exploratory behavior?

This series of experiments examined the effect of clonidine, the $\alpha_{1}$-antagonist prazosin, and the selective depletion of NE by DSP-4 on the restraint-induced decrease in the mean time per contact. We used both acute pharmacological inhibition and lesion of noradrenergic systems to avoid the uncertainties in interpretation of results derived from the use of either of these approachcs individually. Verification of the neurochemical actions of clonidine and DSP-4 was performed by measuring the concentrations of NE and its catabolite, MHPG, using HPLC. with electrochemical detection.

\section{Depletion of cerebral NE antagonized the restraint-induced decrease in exploratory behavior}

Mice were injected with either saline or DSP-4 (50 mg $/ \mathrm{kg}$, i.p.). DSP-4 was chosen rather than 6-hydroxydopamine (6-OHDA) to avoid the surgery and consequent period of recovery from the surgery. To minimize the possibility of compensatory responses following noradrenergic-specific lesions, behavioral testing was conducted $3 \mathrm{~d}$ following the treatment. DSP-4-treated animals with cortical concentrations of $\mathrm{NE}>50 \%$ of the mean of the saline controls were excluded from further analysis (never more than 2 animals per group). In this experiment, DSP -4 depleted NE in cortex by approximately $75 \%$ compared with quiet controls. On the day of testing, saline- and DSP-4treated mice were either removed from their home cages and immediately tested or restrained for $40 \mathrm{~min}$ before testing. Significant main effects of DSP-4 $\left(F_{(1,26)}=45.5, p<0.001\right)$ and restraint $\left(F_{(1,26)}=23.3, p<0.001\right)$ on the mean time per contact were observed (Fig. 1 $A$ ). DSP-4 treatment increased and restraint dccreascd the mean time per contact. Post hoc analysis indicated that the restraint-induced decrease in the mean time per contact was significantly antagonized by DSP-4, but restraint still had a significant effect on this behavior in DSP-4-treated animals. However, the magnitude of the restraint-induced decrease appeared to be less in DSP-4-treated animals (21\%) than in saline-injected animals (48\%). Neither restraint nor DSP-4 
had any significant effects on the number of rears or compartment entries.

\section{Clonidine antagonized the restraint-induced decrease in exploratory behavior}

Unrestrained and restrained mice were injected with either saline or clonidine $(25 \mu \mathrm{g} / \mathrm{kg}$, i.p.) $45 \mathrm{~min}$ before testing. Significant main effects of restraint $\left(F_{(1,28)}=41.7, p<0.001\right)$ and clonidine $\left(F_{(1,28)}=36.3, p<0.001\right)$ were observed for the mean time per contact. Restraint decreased the mean time per contact in salineinjected animals, whereas clonidine increased this measure in unrestrained animals and antagonized the restraint-induced decrease in this response (Fig. $1 B$ ). Restraint significantly decreased the mean time per contact in clonidine-injected animals $(p<0.05)$. However, as observed with DSP-4, the magnitude of this decrease appeared to be less in the clonidine-treated mice ( 26 vs. $41 \%$ ). In this experiment, clonidine significantly decreased the number of compartment entries in unrestrained animals $\left(F_{(1,28)}=6.03, p=0.02\right)$, an effect we had not observed previously with this drug (Berridge and Dunn, 1987b). Restraint had no significant effect on compartment entries. Neither restraint nor clonidine had any significant effects on rearing.

The concentrations of MHPG were increased in NAS, HTH, and HPC in saline-unrestrained animals, and in NAS, HTH, $\mathrm{HPC}$, and BST in saline-restrained mice as compared with quiet controls, suggesting an increased release of $\mathrm{NE}$ in these regions (Table 1). In animals tested in the MCC, ANOVA indicated significant main effects of restraint on MHPG in NAS $\left(F_{(1,26)}=\right.$ $12.5, p=0.001), \operatorname{HTH}\left(F_{(1,27)}=16.8, p<0.001\right)$, and a marginally significant effect in $\mathrm{HPC}\left(F_{(1,26)}=3.8, p=0.058\right)$ such that restraint increased $M H P G$ concentrations compared with unrestrained mice. Main effects of clonidine on MHPG were also observed in those animals tested in the MCC in NAS $\left(F_{(1,26)}\right.$ $=9.8, p=0.004)$, HTH $\left(F_{(1,27)}=18.8, p<0.001\right)$, and HPC $\left(F_{(1.26)}=10.2, p=0.003\right)$. In these 3 regions, clonidine blocked the increase in MHPG in unrestrained animals and significantly attenuated this increase in restrained animals (see Table 1).

\section{Combined treatment with DSP-4 and clonidine prevented the restraint-induced decrease in exploratory behavior}

Because clonidine did not completely block NE release (Table 1) and DSP-4 did not completely deplete NE, and neither treatment prevented the restraint-induced increase in MHPG (data for DSP-4 not shown), these 2 treatments were combined to produce a more effective inhibition of NE release. Mice were treated with either DSP-4 $3 \mathrm{~d}$ before testing and clonidine (25 $\mu \mathrm{g} / \mathrm{kg}$, i.p.) $45 \mathrm{~min}$ before testing or saline at both times. Restrained animals were confined $5 \mathrm{~min}$ after clonidine or saline.

In this experiment, a quiet-control group was not included; however, DSP-4 depleted cortical NE by $65 \%$ compared with saline-unrestrained mice. The less effective depletion observed in this experiment can likely be explained by the fact that exposure to the $\mathrm{MCC}$ alone results in a slight decrease (10-20\%) in cortical NE. Main effects of DSP-4 + clonidine $\left(F_{(1,26)}=32.5\right.$, $p<0.001)$, restraint $\left(F_{(1,26)}=6.65, p<0.015\right)$, and a significant interaction between the $2\left(F_{(1,26)}=4.3, p<0.05\right)$ were observed for the mean time per contact (Fig. 1C). DSP-4 + clonidine increased the mean time per contact in unrestrained animals and completely blocked the effect of restraint on this response. Restraint significantly decreased the number of rears in the DSP-4 + clonidine-treated animals $\left(F_{(1,26)}=6.2, p<0.02\right)$. Neither
A
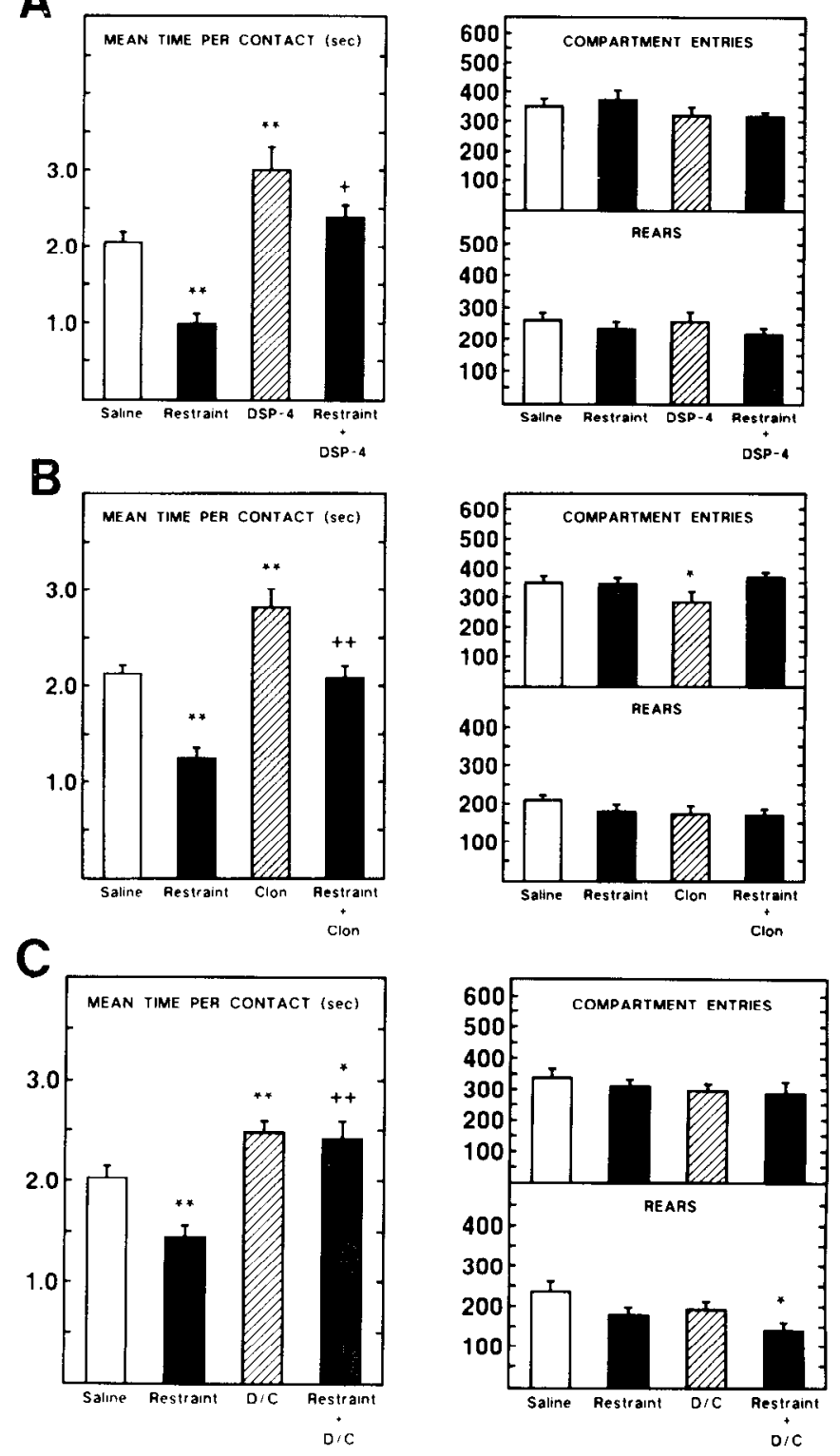

Figure 1. Effect of restraint and DSP-4, clonidine, or DSP-4 + clonidine on the mean time per contact, the total number of rears, and the total number of compartment entries in the MCC. Bars represent means \pm SEM. $A$, Effect of DSP-4 $(50 \mathrm{mg} / \mathrm{kg}$, i.p. $)$ and restraint: saline-unrestrained $(n=8)$, DSP-4-unrestrained $(n=8)$, saline-restrained $(n=7)$, DSP-4-restrained $(n=7)$. $B$, Effect of clonidine $(25 \mu \mathrm{g} / \mathrm{kg}) 45 \mathrm{~min}$ prior to testing $(n=8)$. $C$, Effect of DSP-4 plus clonidine $(25 \mu \mathrm{g} / \mathrm{kg})$ : salineunrestrained $(n=7)$, saline-restrained $(n=8)$, DSP-4/clonidine-unrestrained $(n=9)$, DSP-4/clonidine-restrained $(n=6)$. *Significantly different from saline-unrestrained $\left({ }^{*} p<0.05,{ }^{* *} p<0.01\right)$; ${ }^{+}$significantly different from saline-restrained $\left({ }^{+} p<0.05,{ }^{++} p<0.01\right)$.

restraint nor DSP-4 + clonidine significantly affected the number of compartment entries.

\section{Prazosin prevented the restraint-induced decrease in exploratory behavior}

The above experiments indicated that an activation of noradrenergic systems is involved in mediating the behavioral effect of restraint. To determine whether $\alpha_{1}$-adrenoreceptors were involved in the restraint-induced change in exploratory behavior, the $\alpha_{1}$-antagonist prazosin $(50,100$, or $200 \mu \mathrm{g} / \mathrm{kg}$, i.p.) was ad- 
Figure 2. Effect of prazosin on the restraint-induced changes in behavior in the MCC. Mice were injected with either saline or 50,100 , or $200 \mu \mathrm{g} / \mathrm{kg}$ prazosin 45 min prior to testing $(n=7)$. In relevant groups, mice were restrained 5 min later. Open bars represent unrestrained mice; solid bars, restrained mice. *Significantly different from saline-unrestrained $(p<0.05) ;^{++}$significantly different from saline-restrained $(p<0.01)$.
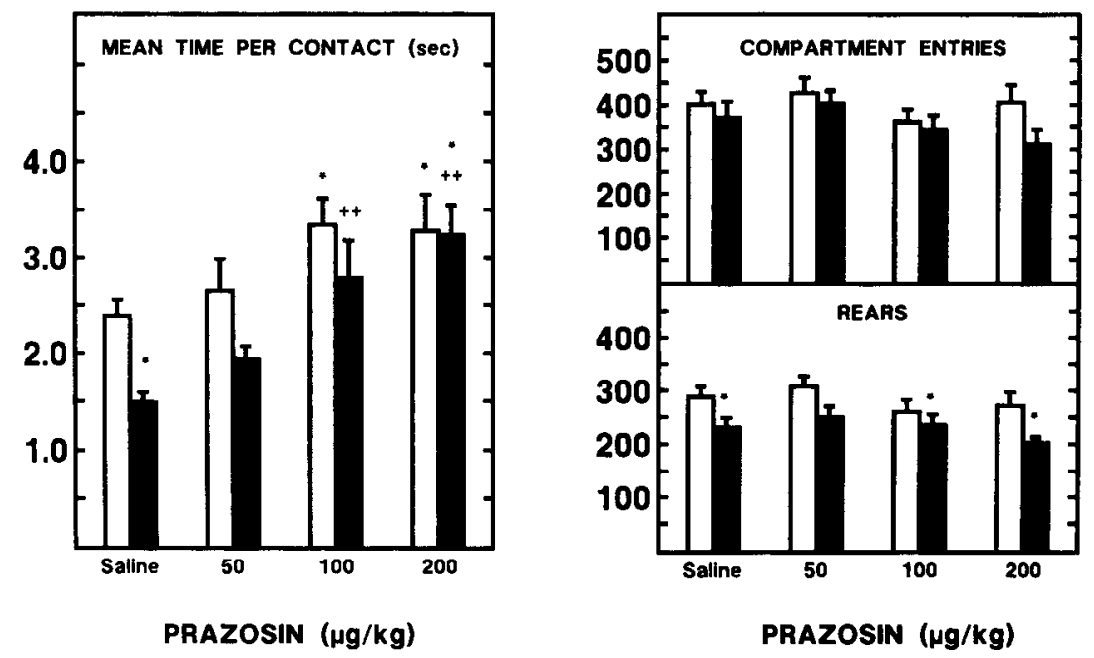

ministered $45 \mathrm{~min}$ before testing restrained and unrestrained mice.

Significant main effects on the mean time per contact (Fig. 2) were observed for both restraint $\left(F_{(1,49)}=8.9, p<0.005\right)$ and prazosin $\left(F_{(3,49)}=11.4, p<0.001\right)$. Restraint significantly decreased the mean time per contact in the saline and $50 \mu \mathrm{g} / \mathrm{kg}$ prazosin groups. In unrestrained mice, prazosin increased the mean time per contact in a dose-dependent manner with a maximum effect observed at the $100 \mu \mathrm{g} / \mathrm{kg}$ dose. Prazosin antagonized the restraint-induced decrease in the mean time per contact in a dose-dependent manner, with a complete blockade at the $200 \mu \mathrm{g} / \mathrm{kg}$ dose. Restraint significantly decreased the number of rears in the saline-treated and 100 and $200 \mu \mathrm{g} / \mathrm{kg}$ prazosintreated animals $\left(F_{(1,49)}=20.0, p<0.001\right)$. In this experiment, a significant main effect of restraint on compartment entries was also observed $\left(F_{(1,49)}=4.2, p<0.05\right)$. However, post hoc analysis indicated that the only significant difference between groups was a decrease in compartment entries in the restrained $+200 \mu \mathrm{g} /$ $\mathrm{kg}$ prazosin group compared with the unrestrained $+200 \mu \mathrm{g} /$ $\mathrm{kg}$ group. Prazosin did not significantly affect either compartment entries or rears.

\section{Phenylephrine decreased exploratory behavior in the MCC}

The reversal of the restraint-induced decrease in stimulus-contact time by an $\alpha_{1}$-antagonist suggested the involvement of $\alpha_{1}$ adrenoreceptors in regulating restraint-induced responding. To test this hypothesis further, mice were injected i.c.v. with either saline or 50 or $100 \mathrm{ng}$ of the $\alpha_{1}$-selective agonist phenylephrine, $10 \mathrm{~min}$ before testing. Both doses of phenylephrine significantly decreased the mcan time per contact with the stimuli $\left(F_{(2,18)}=\right.$ 24.3, $p<0.001$; Fig. 3). Neither dose of phenylephrine had significant effects on the total number of rears or compartment entries.

\section{Responses of cerebral biogenic amines and plasma corticosterone concentrations following exposure to the $\mathrm{MCC}$}

The increased accumulation of MHPG in various brain regions (Table 1) and the increased plasma corticosterone concentrations (data not shown) observed in mice exposed to the MCC resemble those observed in stress. However, in these experiments, the variability of the monoamines and their catabolites was high, probably because the tissues were collected over a number of days and at different times throughout the day, necessitated by the experimental design. Therefore, we tested the effect of a $15 \mathrm{~min}$ exposure to the MCC on the concentrations of plasma corticosterone and brain biogenic amines and their catabolites under temporally controlled conditions. A group exposed to $15 \mathrm{~min}$ footshock was also included to provide a comparison with a well-characterized stressor. Animals were housed singly $3 \mathrm{~d}$ before testing and randomly assigned to 1 of 3 groups: undisturbed, $15 \mathrm{~min}$ period of footshock, or $15 \mathrm{~min}$ period of exposure to the MCC. Footshock consisted of 20-22 1-sec footshocks of $0.2 \mathrm{~mA}$ during the $15 \mathrm{~min}$ period. Immediately foilowing the period of footshock or exposure to the MCC, the

Table 1. Effects of exposure to the MCC and clonidine on the concentration of MHPG in nucleus accumbens (NAS), hypothalamus (HTH), hippocampus (HPC), and brain stem (BST)

\begin{tabular}{lllll} 
Experimental condition & NAS & HTH & HPC & BST \\
\hline Quiet & $0.118 \pm 0.005$ & $0.178 \pm 0.017$ & $0.069 \pm 0.007$ & $0.107 \pm 0.005$ \\
Saline-unrestrained & $0.142 \pm 0.010^{a}$ & $0.234 \pm 0.009^{a}$ & $0.090 \pm 0.003^{a}$ & $0.129 \pm 0.004$ \\
Saline-restrained & $0.173 \pm 0.010^{b}$ & $0.299 \pm 0.017^{b}$ & $0.112 \pm 0.012^{b}$ & $0.159 \pm 0.022^{a}$ \\
Clonidine-unrestrained & $0.113 \pm 0.005$ & $0.151 \pm 0.019$ & $0.066 \pm 0.008$ & $0.127 \pm 0.016$ \\
Clonidine-restrained & $0.146 \pm 0.011^{a, c}$ & $0.220 \pm 0.020^{a, c}$ & $0.079 \pm 0.009^{c}$ & $0.147 \pm 0.032$
\end{tabular}

Mean concentrations of MIIPG expressed as $\mathrm{ng} / \mathrm{mg}$ tissue $( \pm$ SEM). Animals were removed immediately following behavioral testing and NAS, HTH, HPC, and BST were excised.

${ }^{a} p<0.05$.

${ }^{b} p<0.01$ compared with quiet-controls (Dunnett's $t$ test).

' $p<0.05$ compared with saline-restrained (Duncan's multiple range test). 


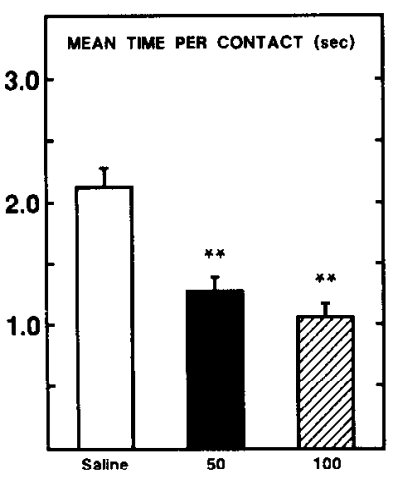

ICV PHENYLEPHRINE (ng)

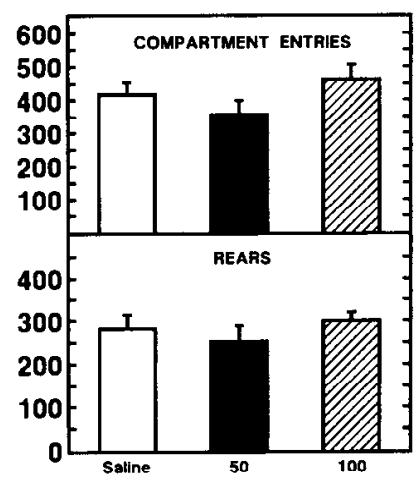

ICV PHENYLEPHRINE (ng)

Figure 3. Effect of phenylephrine on behavior in the MCC. Micc werc injected i.c.v. with either saline or 50 or $100 \mathrm{ng}$ phenylephrine $10 \mathrm{~min}$ prior to testing $(n=7)$. ${ }^{* *}$ Significantly different from saline $(p<0.01)$.

animals were decapitated, trunk blood was collected, and the brain was excised and dissected into PFM, NAS, HTH, and BST. Quiet animals were left in the colony room until immediately before decapitation.

Plasma corticosterone concentrations were $29 \pm 4 \mathrm{ng} / \mathrm{ml}$ in quict mice, and $236 \pm 21$ and $231 \pm 28 \mathrm{ng} / \mathrm{ml}$ in footshocked and $\mathrm{MCC}$-exposed mice, respectively. Both exposure to the MCC and footshock significantly increased the concentrations of plasma corticosterone $\left(F_{(2,20)}=30.6, p<0.001\right)$. Both treatments also increased NE, dopamine (DA), and 5-HT release in certain brain regions, as indicated by increases in the ratio of catabolites to the parent amines. The MHPG:NE, DOPAC:DA, and 5-HIAA:5-HT ratios for PFM, NAS, IITII, and BST expressed as percentage of quiet controls are shown in Figure 4. The MHPG: NE ratio was significantly increased in the PFM of foot-shocked mice $\left(F_{(2,20)}=11.0, p<0.001\right)$ but not of the MCC-exposed animals. This ratio was also significantly increased in both the footshocked and MCC-exposed mice in the $\operatorname{HTH}\left(F_{(2,20)}=43.4\right.$, $p<0.001)$ and $\operatorname{BST}\left(F_{(2,19)}=12.44, p<0.001\right)$. The increased MHPG:NE ratio was significantly greater in the footshock-treated group than in the MCC-exposed group in both the PFM and HTH. The DOPAC:DA ratios were significantly increased by both footshock and exposure to the MCC in NAS $\left(F_{(2,19)}=5.9\right.$, $p=0.01), \operatorname{HTH}\left(F_{(2,20)}=4.2, p=0.03\right)$, and BST $\left(F_{(2,20)}=10.5\right.$, $p<0.001)$. In the PFM, this ratio was significantly increased only in the footshock-treated $\left(F_{(2,20)}=8.7, p=0.002\right)$, and not the MCC-exposed animals. The 5-HIAA:5-HT ratio was significantly increased in the NAS $\left(F_{(2,20)}=6.6, p=0.006\right)$ of both experimental groups.

\section{Are noradrenergic systems involved in the CRF-induced decrease in exploratory behavior?}

To determine whether an activation of noradrenergic systems is involved in the behavioral effect of CRF observed in the MCC, experiments similar to those conducted with restraint were performed with i.c.v. CRF. We first performed a dose-response curve for CRF. Mice were injected i.c.v. with either saline or various doses of CRF $10 \mathrm{~min}$ before testing. A significant effect of CRF on stimulus-contact time was observed $\left(F_{(7,54)}=8.2, p\right.$ $<0.002)$ in the absence of significant effects on compartment entries (Fig. 5). The minimum dose for a significant effect was $5 \mathrm{ng}$. Rears were significantly decreased at the $150 \mathrm{ng}$ dose $\left(F_{(7,54)}\right.$ $=2.2, p<0.045)$. At higher doses $(>200 \mathrm{ng})$, a significant inhibition of compartment entries and rears was observed (data

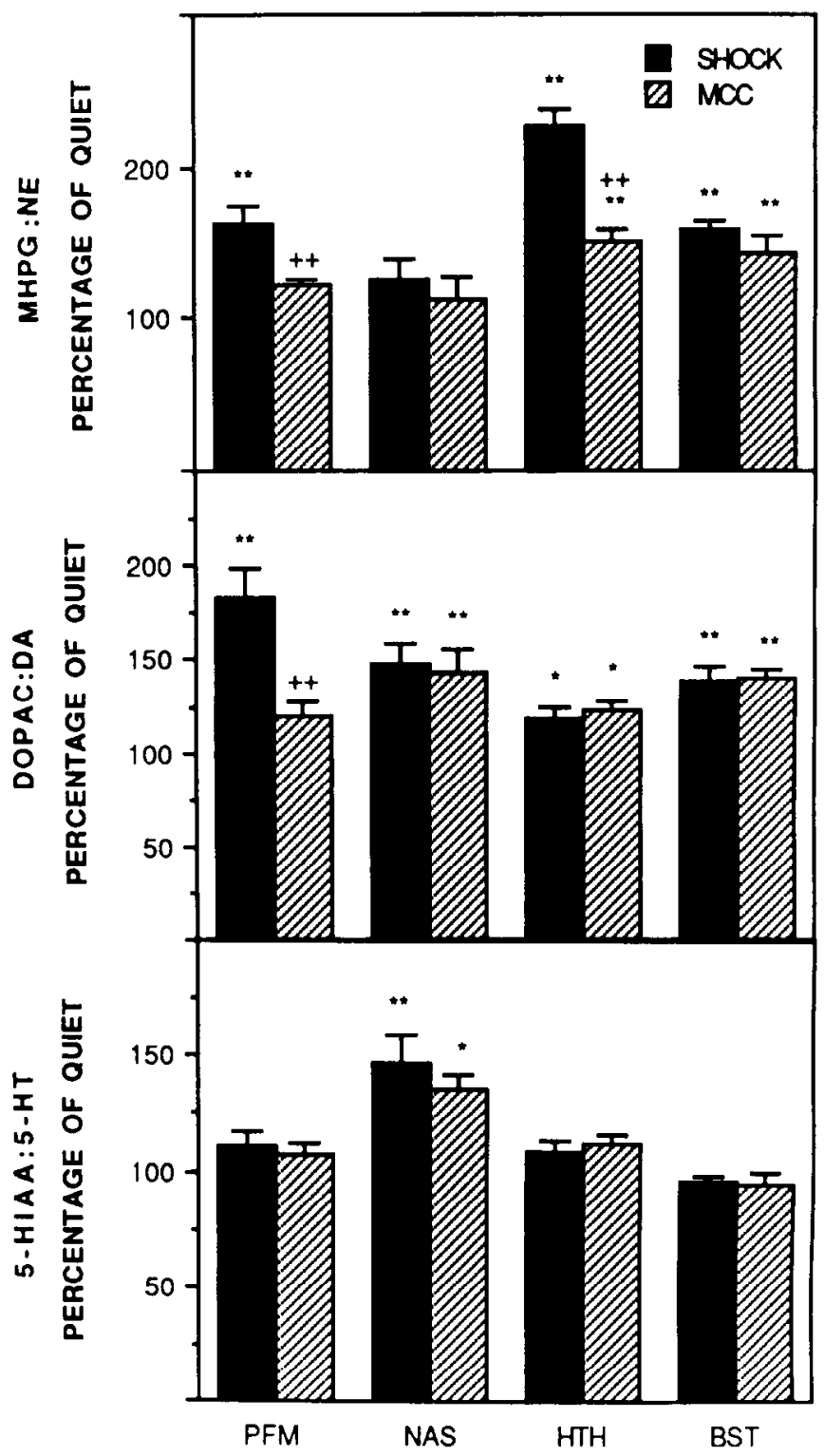

Figure 4. Effect of footshock and exposure to the MCC on the ratios of biogenic amine catabolites to their parent amines in various brain regions. MHPG:NE, DOPAC:DA, and 5-HIAA:5-HT ratios in PFM, NAS, HTH, and BST were determined by HPLC. Bars represent means \pm SEM expressed as percentage of quiet controls $(n=7)$. Mice received either $15 \mathrm{~min}$ of footshock (20-22 $0.15 \mathrm{~mA}$ foot shocks; solid bars, $n=8$ ) or were placed in the MCC for 15 min (shaded bars, $n=8$ ). *Significantly different from quiet-controls $\left({ }^{*} p<0.05,{ }^{* *} p<0.01\right)$; ${ }^{+}$significantly different from footshocked mice $\left(p<0.05,{ }^{1} p<0.01\right)$

not shown). Based on these results, $20 \mathrm{ng}$ was selected for use in this series of experiments.

\section{Depletion of cerebral NE did not affect the CRF-induced decrease in exploratory behavior}

Mice that had been injected with either saline or DSP-4 $3 \mathrm{~d}$ previously were injected i.c.v. with either saline or CRF $10 \mathrm{~min}$ before testing. DSP-4 significantly decreased cortical NE by approximately $75 \%$ compared with quiet controls. Significant main effects of CRF $\left(F_{(1,24)}=52.3, p<0.001\right)$ and DSP-4 $\left(F_{(1,24)}=\right.$ $5.8, p<0.03)$ and a significant interaction between the $2\left(F_{(1,24)}\right.$ $=10.6, p=0.003)$ were observed for the mean time per contact (Fig. 6A). DSP-4 increased the mean time per contact with the 


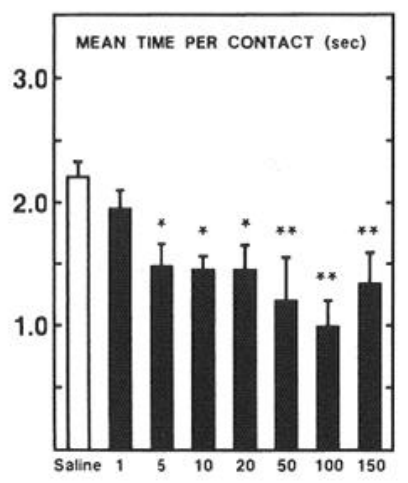

ICV CRF (ng)

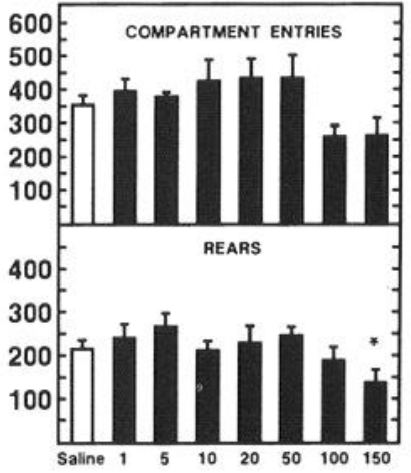

ICV CRF (ng)
Figure 5. Dose-response for CRF-induced changes of behavior in the MCC. Mice were injected i.c.v. with either saline $(n=9)$ or $1(n=7)$, $5(n=7), 10(n=7), 20(n=8), 50(n=7), 100(n=7)$, or $150 \mathrm{ng}(n$ $=10) \mathrm{CRF} 10 \mathrm{~min}$ prior to a $30 \mathrm{~min}$ testing period. *Significantly different from saline $\left({ }^{*} p<0.05,{ }^{* *} p<0.01\right)$.

stimuli in saline-injected animals. CRF significantly decreased the mean time per contact in animals injected with either saline or DSP-4. There was no observable effect on this response of DSP-4 in CRF-injected animals, presumably accounting for the significant interaction term. Neither CRF nor DSP-4 significantly affected the number of rears. In this experiment, DSP-4 significantly decreased the number of compartment entries in both the saline- and CRF-injected groups, effects not observed previously (e.g., Fig. 1A).

\section{Prazosin did not affect the CRF-induced decrease in exploratory behavior}

Mice were injected with either saline or $200 \mu \mathrm{g} / \mathrm{kg}$ prazosin 5 min before an i.c.v. injection of either saline or CRF. Mice were tested $10 \mathrm{~min}$ following the i.c.v. injection. Again, significant main effects of prazosin $\left(F_{(1,28)}=7.9, p=0.008\right)$ and $\operatorname{CRF}\left(F_{(1,28)}\right.$ $=86.3, p<0.001)$ and a significant interaction between them $\left(F_{(1,28)}=11.2, p=0.002\right)$ were observed for the mean time per contact (Fig. $6 B$ ). Prazosin significantly increased the mean time per contact in saline-injected mice. CRF significantly decreased the mean time per contact in both the saline- and prazosininjected groups. Prazosin had no effect on the CRF-induced decrease in the mean time per contact. Neither CRF nor prazosin had any effect on the number of rears or compartment entries.

\section{Is CRF involved in the NE-stimulated decrease in exploratory behavior? \\ ahCRF reversed the phenylephrine-induced decrease in exploratory behavior}

The above results together with our previous observations indicated that both CRF and NE are involved in the restraintinduced decrease in stimulus-contact time and that noradrenergic systems are not involved in the behavioral effect of CRF in this paradigm. To test whether NE stimulates CRF release to alter behavior, we examined the effect of ahCRF on the phenylephrine-induced decrease in the mean time per contact.

Mice were injected i.c.v. $(2 \mu \mathrm{l})$ with either saline or $20 \mu \mathrm{g}$ ahCRF $5 \mathrm{~min}$ before a second i.c.v. injection $(2 \mu \mathrm{l})$ of either saline or 50 or $100 \mathrm{ng}$ phenylephrine. The animals were tested $10 \mathrm{~min}$ after the second injection. Phenylephrine significantly decreased the mean time per contact in animals that were first
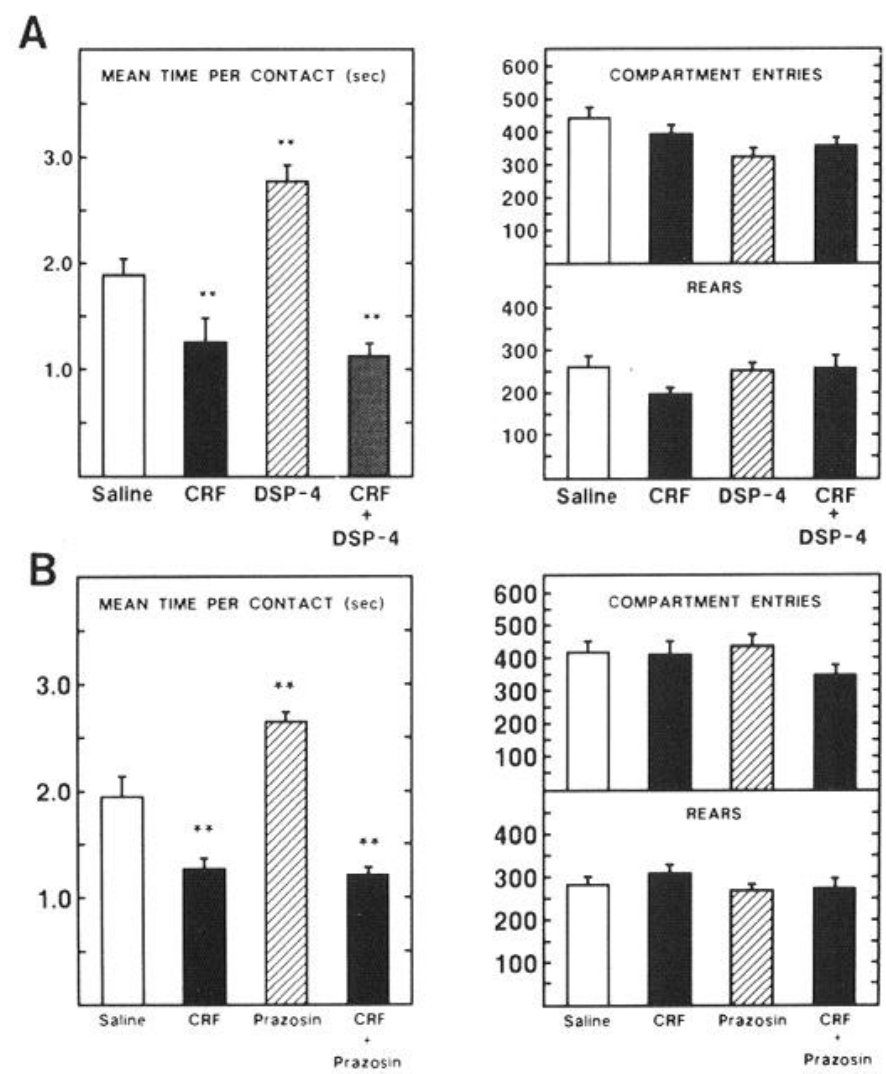

Figure 6. Effect of DSP-4 and prazosin on the CRF-induced changes in behavior in the MCC. $A$, Mice were injected with either saline or DSP-4 3 d before testing. On the day of testing, saline- and DSP-4injected mice were injected i.c.v. with either saline or $20 \mathrm{ng}$ CRF 10 min prior to testing $(n=7)$. $B$, Mice were injected i.c.v. with either saline or $20 \mathrm{ng}$ CRF $5 \mathrm{~min}$ after receiving an i.p. injection of either saline or $200 \mu \mathrm{g} / \mathrm{kg}$ prazosin. Animals were tested $10 \mathrm{~min}$ following the i.c.v. injection $(n=8)$. ${ }^{* *}$ Significantly different from saline-saline $(p<$ $0.01)$.

injected with saline $\left(F_{(2,40)}=6.0, p=0.005\right.$; Fig. 7). A main effect of ahCRF on this behavior was also observed $\left(F_{(1,40)}=\right.$ $17.9, p<0.001)$. The CRF antagonist produced a slight but nonsignificant increase in the mean time per contact in animals receiving saline on the second injection. This effect of the antagonist in otherwise untreated animals resembles that observed previously (Berridge and Dunn, 1987a). ahCRF completely blocked the phenylephrine-induced decrease in the mean time per contact (Fig. 7). Neither phenylephrine nor ahCRF had any significant effects on the number of rears or compartment entries.

\section{Discussion}

As previously reported (Berridge and Dunn, 1986), restraint stress decreased the time mice spent investigating objects in a novel environment without consistent effects on locomotor activity. This effect was mimicked by the $\alpha_{1}$-selective agonist phenylephrine, injected i.c.v. (Fig. 6), and the $\alpha_{2}$-antagonist idazoxan (Berridge and Dunn, 1987b). In contrast, treatments that inhibit NE release (DSP-4, clonidine; Fig. 1) or block $\alpha_{1}$-receptors (prazosin; Fig. 2) increased this exploratory activity and diminished or prevented the restraint-induced decrease in this behavior. The ability of phenylephrine to mimic the restraint-induced change in behavior and that of prazosin to prevent it suggest that the effect of restraint involves an activation of cerebral $\alpha_{1}$ adrenoreceptors. 
CRF given i.c.v. elicited a dose-dependent, stress-like decrease in the mean time per contact with a minimum effective dose of $5 \mathrm{ng}$ (Fig. 5). Conversely, the CRF antagonist ahCRF blocked the restraint-induced decrease in the mean time per contact, indicating a role of endogenous CRF in this behavioral effect of restraint (Berridge and Dunn, 1987a). Thus, these results taken together, suggest that activations of both CRF and NE systems are involved in the restraint-induced decrease in exploratory behavior in the MCC.

Neither prazosin nor DSP-4 altered the CRF-induced decrease in exploratory behavior (Fig. 6). However, ahCRF reversed the phenylephrine-induced decrease in stimulus-contact time (Fig. 7). These results suggest that NE and CRF systems interact, such that NE stimulates the release of CRF to influence behavior in the MCC. Because there was no additivity between the behavioral effect of either prazosin or DSP-4 and that of CRF, CRF and NE apparently do not act as independent parallel systems.

Untreated animals exposed to the MCC displayed increased accumulations of MHPG (Table 1) and MHPG:NE ratios (Fig. 4) in a number of brain regions, presumably indicating an increased release of NE. This would explain why treatments that inhibit noradrenergic activity (e.g., DSP-4 and clonidine, Fig. 1) increased stimulus-contact times in unrestrained animals. In addition, the plasma corticosterone concentrations and the ratios of DOPAC:DA and 5-HIAA:5-HT were also increased in a number of brain regions (Fig. 4). Because an increased release of corticosterone and brain monoamines are responses characteristic of stress, exposure to the MCC can be considered a stressor (Dunn and Kramarcy, 1984). This would explain why ahCRF slightly elevated the mean time per contact in unrestrained mice (Fig. 7; Berridge and Dunn, 1987a).

It is unlikely that the behavioral effects of the treatments used in these studies result from peripheral actions. Although both stress and i.c.v. CRF activate the pituitary-adrenal axis, hypophysectomy did not attenuate the effect of either restraint or CRF observed in the MCC (Berridge and Dunn, 1989). Moreover, the dose of CRF used in these studies is below that required to increase either adrenal sympathetic nerve activity (Kurosawa et al., 1986) or blood pressure and heart rate in the rat (Fisher et al., 1982). Furthermore, phenylephrine ( 50 or $100 \mathrm{ng}$ ) injected i.c.v. decreased stimulus-directed behavior, whereas 100 or 200 $\mu \mathrm{g} / \mathrm{kg}$ was devoid of behavioral effects when injected i.p. (data not shown).

Arnsten et al. (1981) examined the effect of 6-OHDA lesions of the noradrenergic bundle on exploratory behavior of rats in the MCC. They observed a significant decrease in the mean time per contact in lesioned animals, an effect opposite that we observed using DSP-4. However, their rats were tested at least 14 $\mathrm{d}$ after the 6-OHDA injection, at a time when compensatory responses within noradrenergic systems are known to occur (U'Prichard et al., 1980; Logue et al., 1985). When the 6-OHDA rats were tested 2-4 d postlesion, an increased mean time per contact was observed (Arnsten ct al., 1981). Although this increase in the mean time per contact was not statistically significant, it was similar in magnitude to that we observed in DSP4-treated mice. Further, when we observed mice $10 \mathrm{~d}$ after DSP-4 treatment, they displayed a significantly decreased mean time per contact ( $1.5 \pm 0.2$ vs. $2.3 \pm 0.2 \mathrm{sec}$ ), an effect opposite that observed $3 \mathrm{~d}$ after DSP-4 treatment and consistent with that observed by Arnsten et al. Thus, we believe that the effects observed 10-14 d following treatment with either 6-OHDA or

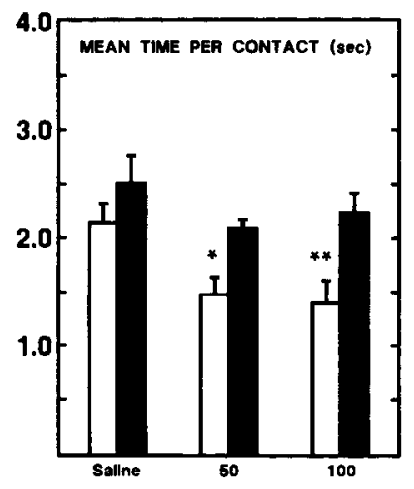

ICV PHENYLEPHRINE (ng)

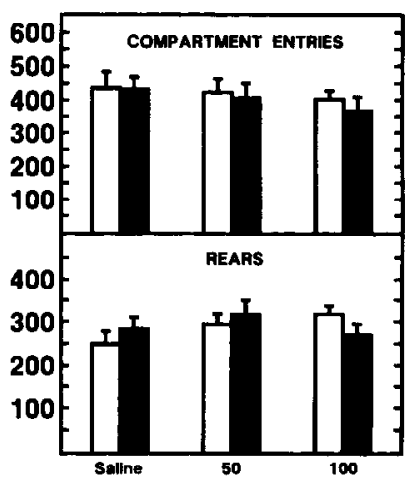

ICV PHENYLEPHAINE (ng)
Figure 7. Effect of ahCRF on the i.c.v. phenylephrine-induced changes in behavior in the MCC. Mice were injected i.c.v. with either saline (open bars) or $20 \mu \mathrm{g}$ ahCRF (solid bars). Five minutes later they were injected i.c.v. with either saline or phenylephrine (50 or $100 \mathrm{ng}$ ). Salinesaline $(n=8)$, saline-50 $(n=8)$, or saline-100 ng phenylephrine $(n=$ 7), ahCRF-saline $(n=8)$, ahCRF-50 $(n=8)$, ahCRF-100 ng phenylephrine $(n=7)$. Animals were tested $10 \mathrm{~min}$ following the second injection. *Significantly different from saline-saline $\left({ }^{*} p<0.05,{ }^{* *} p<\right.$ $0.01)$.

DSP-4 reflect a lesion-induced hyperresponsivity of noradrenergic systems.

Our conclusion that noradrenergic neurons stimulate CRF release to influence behavior is opposite that predicted based on the i.c.v. CRF-induced increases of locus coeruleus firing (Valentino et al., 1983) and brain MHPG (Dunn and Berridge, 1987). However, these stimulatory effects of CRF on noradrencrgic activity werc obscrved only at doses substantially higher than those needed to elicit a behavioral effect in the MCC. At these higher doses, mice tested in the MCC show a very different response profile, including a pronounced hypoactivity and associated postural changes (Berridge and Dunn, 1987a). Thus, although NE and CRF may interact mutually (i.e., NE-mediated release of CRF and vice versa), each interaction may affect different responses.

The stimulatory effect of NE on CRF release suggested by the present studies is consistent with the known mechanisms regulating CRF release into the portal blood supply in both the rat (Plotsky, 1987; Szafarczyk et al., 1987) and man (Al-Damluji and Rees, 1987). Stimulation of the ventral noradrenergic bundle (Plotsky, 1987) or injection of NE into the lateral ventricles or directly into the PVN stimulated the release of CRF into the portal blood supply (Plotsky, 1987; Szafarczyk et al., 1987). The stimulatory effect of these treatments on CRF release was prevented by the $\alpha_{1}$-antagonists prazosin (Szafarczyk et al., 1987) and coryanthine (Plotsky, 1987). Thus, the pharmacology of this system resembles that involved in stress-related changes in exploratory behavior. It is possible that collaterals from CRFcontaining cells within the PVN are involved in regulating this behavioral response. Consistent with this hypothesis, the PVN has bcen shown to be a critical site in regulating the CRFinduced decrease in feeding behavior and injection of CRF into the PVN increased grooming and locomotor activity (Krahn et al., 1988). Alternatively, noradrenergic terminals in other regions could regulate the release of CRF elsewhere in the brain. For example, certain telencephalic structures that receive a particularly dense innervation from the dorsal noradrenergic bundle (see Nieuwenhuys, 1985) also contain high densities of CRFcontaining cells (e.g., the amygdala and portions of the neocortex 
(Merchenthaler, 1984)). The fact that DSP-4 primarily affects fibers of the DNB (Jonsson et al., 1981) suggests that CRF affects exploratory behavior by acting within the telencephalon, although other sites cannot be excluded.

The involvement of NE in stress-induced behavior in the MCC is consistent with the reported involvement of NE in emotional and behavioral responding associated with anxiety in humans (Hoehn-Saric et al., 1981; Charney et al., 1984) and nonhuman primates (Redmond and Huang, 1979). For example, monkeys in which the locus coeruleus was electrically stimulated or that received the $\alpha_{2}$-antagonists piperoxan or yohimbine displayed fear-associated behaviors (Redmond and Huang, 1979). In rats, clonidine decreased the potentiated startle response (Davis et al., 1977) and increased punished responding in the Geller-Seifter conflict test (Kruse et al., 1981). Consistent results were obtained in the elevated X-maze (Handley and Mithani, 1984). These effects are all consistent with an anxiogenic action of noradrenergic systems. The results obtained with mice in the MCC extend the hypothesis that NE is a mediator of behavioral responding associated with anxiety by suggesting that NE stimulates the release of CRF, which through an as yet undefined mechanism affects behavior.

There is evidence suggesting that stress (Anisman and $\mathrm{Za}$ charko, 1982) and NE (Stone, 1983; Weiss et al., 1985) are etiological factors in depression. Recently, abnormalities in CRF functions have also been implicated in this disorder. Thus, a high proportion of patients with depression exhibit a hyperactivity of the hypothalamic-pituitary-adrenal axis and an insensitivity to CRF-induced ACTH secretion (Gold and Chrousos, 1985). Further, elevated concentrations of CSF CRF were observed in depressed patients but not schizophrenics, and there was a reduction in the number of CRF-binding sites in the frontal cortex of suicide victims (Nemeroff, 1988). Furthermore, a significant positive correlation between the CSF concentration of CRF and urinary NE and its catabolites was observed in depressed patients (Roy et al., 1987). A trend for a significant correlation between CSF CRF and CSF NE was observed in these same patients. These results suggest that CRF may be associated with the dysregulation of noradrenergic systems thought to occur in depression. Therefore, the possibility that NE regulates CRF release, which in turn modifies behavior in the MCC, provides further support for studies examining dysregulation of NE-CRF interactions in depression.

\section{References}

Al-Damluji, S., and L. H. Rees (1987) Effects of catecholamines on secretion of adrenocorticotropin hormone (ACTH) in man. J. Clin. Pathol. 40: 1098-1107.

Anisman, H., and R. M. Zacharko (1982) Depression: The predisposing influence of stress. Behav. Brain Sci. 5: 89-137.

Arnsten, A. F. T., C. Berridge, and D. S. Segal 1985) Stress produces (1981) Evidence for an interaction of opioid and noradrenergic locus coeruleus systems in the regulation of environmental stimulus-directed behavior. Brain Res. 222: 351-363.

Arnsten, A. F. T., C. Berridge, and D. S. Segal (1985) Stress produces opioid-like effects on investigatory behavior. Pharmacol. Biochem. Behav. 22: 803-809.

Berridge, C. W., and A. J. Dunn (1986) Corticotropin-releasing factor elicits naloxone-sensitive stress-like alterations in exploratory behavior in mice. Regulat. Peptides 16: 83-93.

Berridge, C. W., and A. J. Dunn (1987a) A corticotropin-releasing factor antagonist reverses the stress-induced changes of exploratory behavior in mice. Horm. Behav. 21:393-401.

Berridge, C. W., and A. J. Dunn (1987b) $\alpha_{2}$-noradrenergic agonists and antagonists alter exploratory behavior in mice. Neurosci. Res. Commun. 1: 97-103.

Berridge, C. W., and A. J. Dunn (1989) CRF and restraint stress decrease exploratory behavior in hypophysectomized mice. Pharmacol. Biochem. Behav. (in press).

Brown, M. R., L. A. Fisher, J. Spicss, C. Rivier, J. Rivier, and W. Vale (1982) Corticotropin-releasing factor: Activities on the sympathetic nervous system and metabolism. Endocrinology 111: 928-931.

Brown, M. R., L. A. Fisher, V. Webb, W. W. Vale, and J. E. Rivier (1986) Corticotropin-releasing factor: A physiologic regulator of adrenal epinephrine secretion. Brain Res. 328: 355-357.

Charney, D. S., G. R. Heninger, and A. Breier (1984) Noradrenergic function in panic anxiety. Effects of yohimbine in healthy subjects and patients with agoraphobia and panic disorder. Archs. Gen. Psychiatry 41: 751-763.

Davis, M., J. M. Cedarbaum, G. K. Aghajanian, and D. S. Gendelman (1977) Effects of clonidine on habituation and sensitization of acoustic startle in normal, decerebrate and LC lesioned rats. Psychopharmacology 51: 243-253.

Dunn, A. J., and N. R. Kramarcy (1984) Neurochemical responses in stress: Relationships between the hypothalamic-pituitary-adrenal and catecholamine systems. In Handbook of Psychopharmacology, Vol. 18, L. L. Iversen, S. D. Iversen, and S. H. Snyder, eds., pp. 455-515, Plenum Press, New York.

Dunn, A. J., and C. W. Berridge (1987) Corticotropin-releasing factor administration elicits a stress-like activation of cerebral catecholaminergic systems. Pharmacol. Biochem. Behav. 27: 685-691.

Dunn, A. J., K. L. Elfvin, and C. W. Berridge (1986) Changes in plasma corticosterone and cerebral biogenic amines and their catabolites during training and testing of mice in passive avoidance behavior. Behav. Neural Biol. 46: 410-423.

Fisher, L. A., J. Rivier, C. Rivier, J. Spiess, W. Vale, and M. R. Brown (1982) Corticotropin-releasing factor (CRF): Central effects on mean arterial pressure and heart rate in rats. Endocrinology 110: 22222224.

Gold, P. W., and G. P. Chrousos (1985) Clinical studies with corticotropin releasing factor: Implications for the diagnosis and pathophysiology of depression, Cushing's disease, and adrenal insufficiency. Psychoneuroendocrinology 10: 401-419.

Goldstein, J. M., L. C. Knobloch, and J. B. Malik (1983) Electrophysiological demonstration of both $\alpha_{2}$-agonist and antagonist properties of RX 781094. Eur. J. Pharmacol. 91: 101-105.

Guild, A. L., and A. J. Dunn (1982) Dopamine involvement in ACTHinduced grooming behavior. Pharmacol. Biochem. Behav. 17:31-36.

Gwosdow-Cohen, A., C. L. Chen, and E. I. Besch (1982) Radioimmunoassay (RIA) of serum corticosterone in rats. Proc. Soc. Exp. Biol. Med. 170: 29-34.

Handley, S. L., and S. Mithani (1984) Effects of alpha-adrenoceptor agonists and antagonists in a maze-exploration model of "fear"-motivated behaviour. Naunyn Schmiedebergs Arch. Pharmacol. 327: $1-5$.

Hoehn-Saric, R., A. F. Merchant, M. L. Keyser, and V. K. Smith (1981) Effects of clonidine on anxiety disorders. Arch. Gen. Psychiatry 38: $1278-1286$.

Jonsson, G., H. Hallman, F. Ponzio, and S. Ross (1981) DSP-4 (N(2-chloroethyl)-N-ethyl-2-bromobenzylamine)-a useful denervation tool for central and peripheral noradrenaline neurons. Eur. J. Pharmacol. 72: 173-188.

Kalin, N. H., S. E. Shelton, G. W. Kraemer, and W. T. McKinney (1983) Corticotropin-releasing factor administered intraventricularly to rhesus monkeys. Peptides 4: 217-220.

Koob, G. F., and F. E. Bloom (1985) Corticotropin-releasing factor and behavior. Fed. Proc. 44: 259-263.

Krahn, D. D., B. A. Gosnell, M. Grace, and A. S. Levine (1986) CRF antagonist partially reverscs CRF- and stress-induced effects on feeding. Brain Res. Bull. 17: 285-289.

Krahn, D. D., B. A. Gosnell, A. S. Levine, and J. E. Morley (1988) Behavioral effects of corticotropin-releasing factor: Localization and characterization of central effects. Brain Res. 443: 63-69.

Kruse, H., R. W. Dunn, K. L. Theurer, W. J. Novick, and G. T. Shearman (1981) Attenuation of conflict induced suppression by clonidine: Indication of anxiolytic activity. Drug Dev. Res. 1: 137-143.

Kurosawa, M., A. Sato, A. S. Swenson, and Y. Takahashi (1986) Sympatho-adrenal medullary functions in response to intracerebroven- 
tricularly injected corticotropin-releasing factor in anesthetized rats. Brain Res. 367: 250-257.

Logue, M. P., J. H. Growdon, I. L. G. Coviella, and R. J. Wurtman (1985) Differential effects of DSP-4 administration on regional brain norepinephrine turnover in rats. Life Sci. 37: 403-409.

Merchenthaler, I. (1984) Corticotropin releasing factor (CRF)-like immunoreactivity in the rat central nervous system. Extrahypothalamic distribution. Peptides 5: 53-69.

Morley, J. E., and A. S. Levine (1982) Corticotrophin releasing factor, grooming and ingestive behavior. Life Sci. 31: 1459-1464.

Nemeroff, C. B. (1988) The role of corticotropin-releasing factor in the pathogenesis of major depression. Pharmacopsychiatry $21: 76-$ 82.

Nieuwenhuys, R. (1985) In Chemoarchitecture of the Brain, p. 22, Springer-Verlag, Berlin.

Plotsky, P. M. (1987) Facilitation of immunoreactive corticotropinreleasing factor secretion into the hypophysial-portal circulation after activation of catecholaminergic pathways or central norepinephrine injection. Endocrinology 121: 924-930.

Redmond, D. E., and Y. H. Huang (1979) New evidence for a locus coeruleus-norepinephrine connection with anxiety. Life Sci. 25:21492162.

Rivier, J., C. Rivier, and W. Vale (1984) Synthetic competitive antagonists of corticotropin-releasing factor: Effects on ACTH secretion in the rat. Science 224: 889-891.

Rivier, C., J. Rivier, and W. Vale (1986) Stress-induced inhibition of reproductive functions: Role of endogenous corticotropin-releasing factor. Science 231: 607-609.

Roy, A., D. Pickar, M. Linnoila, G. P. Chrousos, and P. W. Gold (1987) Cerebrospinal fluid corticotropin-releasing hormone in depression: Relationship to noradrenergic function. Psychiatr. Res. 20: 229-237.

Scheinin, H., and R. Virtanen (1986) Effects of yohimbine and idazoxan on monoamine metabolites in rat cerebrospinal fluid. Life Sci. 39: $1439-1446$

Smith, M. A., T. A. Slotkin, D. L. Knight, and C. B. Nemeroff (1986) Release of corticotropin-releasing factor from rat brain regions in vitro. Endocrinology 118: 1997-2001.

Stone, E. A. (1975) Stress and catecholamines. In Catecholamines and Behavior, Vol. 2: Neuropsychopharmacology, A. J. Friedhoff, ed., pp. 31-72, Plenum Press, New York.
Stone. E. A. (1983) Problems with current catecholamine hypotheses of antidepressant agents: Speculations leading to a new hypothesis. Behav. Brain Sci. 6: 535-577.

Sutton, R. E., G. F. Koob, M. Le Moal, J. Rivier, and W. Vale (1982) Corticotropin releasing factor produces behavioural activation in rats. Nature 297: 331-333.

Svensson, T. H., B. S. Bunney, and G. K. Aghajanian (1975) Inhibition of both noradrenergic and serotonergic neurones in brain by the $\alpha$-adrenergic agonist clonidine. Brain Res. 92: 291-306.

Swanson, L. W., P. E. Sawchenko, J. Rivier, and W. W. Vale (1983) Organization of ovine corticotropin-releasing factor immunoreactive cells and fibers in the rat brain: An immunohistochemical study. Neuroendocrinology 36: 165-186.

Szafarczyk, A., F. Malaval, A. Laurent, R. Gihaud, and I. Assenmacher (1987) Further evidence for a central stimulatory action of catecholamines on adrenocorticotropin release in the rat. Endocrinology 121: 883-892.

Tazi, A., R. Dantzer, M. Le Moal, J. Rivier, W. Vale, and G. F. Koob (1987) Corticotropin-releasing factor antagonist blocks stress-induced fighting in rats. Regulat. Peptides 18: 37-42.

U'Prichard, D. C., T. D. Reisine, S. T. Mason, H. C. Fibiger, and H. I. Yamamura (1980) Modulation of rat brain alpha- and $\beta$-adrenergic receptor populations by lesion of the dorsal noradrenergic bundle. Brain Res. 187: 143-154.

Valentino, R. J., S. L. Foote, and G. Aston-Jones (1983) Corticotropinreleasing factor activates noradrenergic neurons of the locus coeruleus. Brain Res. 270: 363-367.

Warsh, J. I., P. P. Li, D. D. Godse, and S. Cheung (1981) Brain noradrenergic neuronal activity affects 3,4-dihydroxyphenylethyleneglycol (DHPG) levels. Life Sci. 29: 1303-1307.

Weiss, J. M., P. G. Simson, M. J. Ambrose, A. Webster, and L. J. Hoffman (1985) Neurochemical basis of behavioral depression. Adv. Behav. Med. 1: 233-275.

Wynn, P. C., R. L. Hauger, M. C. Holmes, M. A. Millan, K. J. Catt, and G. Aguilera (1984) Brain and pituitary receptors for corticotropin releasing factor: Localization and differential regulation after adrenalectomy. Peptides 5: 1077-1084. 